\section{CONFOCAL Microscopy Listserver}

Robert Summers, SUNY Buffalo

The CONFOCAL microscopy listserver discussion group was put on the air over 5 years ago by Don Parsons (Albany), Steve Paddock (Wisconsin), P.C. Cheng (Buffalo) and me at the suggestion of Parsons that there should be an open discussion forum for this rapidly developing technology. Parsons is an expert in infomatics (among other things) and appreciated the potential of the "mail reflector" concept at an early stage in its development.

Listserver groups were pretty uncommon then but we figured that since we were dealing with digital microscopists, most of those interested would have computers and access to Bitnet or Internet. For the first month or so Parsons, Paddock, Cheng and I corresponded with one another to work wrinkles out of the system and we then began to publicize the existence of the group at meetings, symposia and through the commercial manufacturers of confocal microscopes and associated hardware.

Topics considered by the group have been wide ranging, including discussions of fluorochromes, lasers, point spread functions, software, optics, color printers, resolution, CCD cameras, volume rendering, and frame stores to name just a few. We encourage postings on meetings relevant to confocal microscopy and 3-D imaging, and postings of positions available in the area.

The group now has over 400 members worldwide and we welcome anyone interested in the area of confocal microscopy and 3-D imaging. All of the major microscopy and software companies are subscribers and respond actively to questions and criticism of their products. However, "commercials" are prohibited. Archives of discussions for the past year are maintained and are accessible to the public.

To subscribe, send a message to either:

LISTSERV@ubvm.cc.buffalo. edu (Internet) or

LISTSERV@ubvm.bitnet (Bitnet).
Ignore subject and on the first message line type:

Subscribe Confocal (Your Name - actual, not eMail).

The listserver utility in Buffalo will acknowledge your subscription, send instructions on how to use the list (please print them for later use) and place you on the list.

To send MAIL MESSAGES to the 400 plus subscribers, send to:

CONFOCAL@ubvm.cc.buffalo.edu (Internet) or

CONFOCAL @ubvm.bitnet (Bitnet)

If you have any questions about the list, please do not hesitate to contact me by telephone (716/829-2911) or eMail (Summers@ubmed.buffalo.edu).

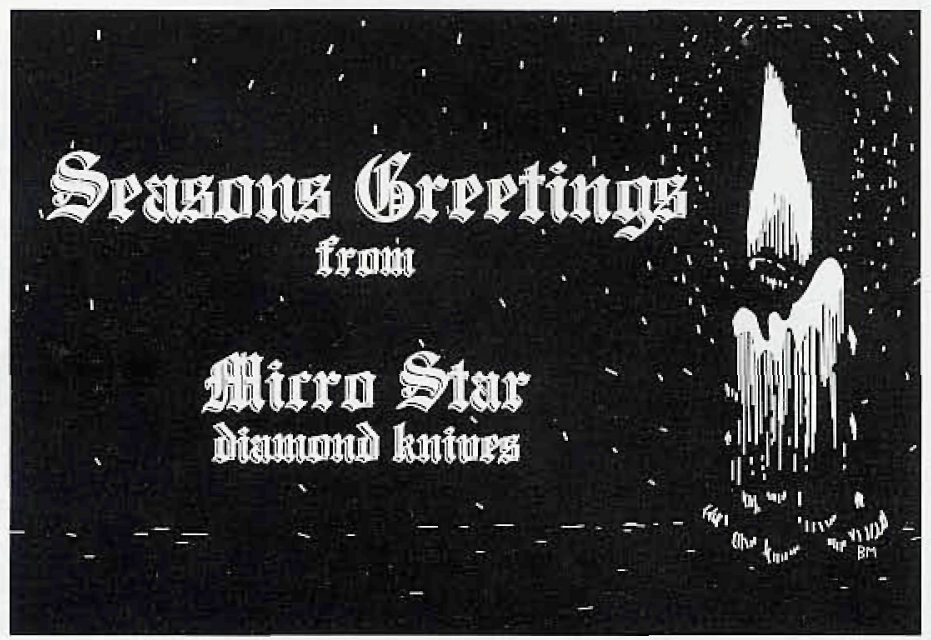

\section{Top Light With The Polarizing Microscope}

Walter C. McCrone, McCrone Research Institute

To adequately microscopically characterize opaque particles, and some finely divided, high refractive index, and transparent particles, one must use top light. This can be done with a built-in or accessory vertical illuminator. It can also be done without a vertical illuminator using any PLM with any separate microscope illuminator focusable to a small bright spot. Aimed downward onto the slide preparation at a steep angle, but missing the objective, and with the transillumination subdued or turned off, the color and surface texture of opaque particles can be readily discerned. The objective must have a long working distance, usually, therefore, a $10 \mathrm{X}$ or lower magnification.

Pseudo opaque particles (submicrometer particles of high index) are really transparent but hey may be colorless or any color. Top light brings out their true color - black, if opaque, but they may be red $\left(\mathrm{Fe}_{2} \mathrm{O}_{3}\right)$, green $\left(\mathrm{CR}_{2} \mathrm{O}_{3}\right)$, yellow (leadtin yellow) or white $\left(\mathrm{TiO}_{2}\right)$. All particles, if high index and submicrometer, may appear to be opaque. The same top light used above with the $10 \mathrm{X}$ objective can also be used with any higher power dry objective. Simply turn off the transillumination, turn up the top light voltage and aim it as though you were using the $10 \mathrm{X}$ objective. Enough light will reflect back and forth from objective to coverslip and ultimately to the particles to show their colors.

With a polarizing microscope, it is usually unnecessary to use a top light. If the substage and field aperture diaphragms are wide open and the transillumination light intensity is high, top light is obtained by reflection from the objective front lens. It is sufficiently bright to see colors, if the polars are first crossed to darken the background.

Finally, an unusual and unplanned form of top light is obtained with the Wild stereobinocular microscopes equipped with a $2 X$ auxiliary illuminator having a concave front lens and a transillumination base. Light from the mirror passes upward through the object space to the concave objective front lens where it is reflected back onto the specimen illuminating any opaque specimen. This is particularly helpful for mounting single particles on SEM stubs or beryllium microprobe plates (see the Particle Atlas Volume I, p. 239). 